69 Management of chronic suppurative otitis media with cholesteatoma

A Intact canal wall mastoidectomy gives excellent access to the sinus tympani.

B A posterior tympanotomy provides access to the mesotympanum and hypotympanum by dissection of the facial recess.

C Combined approach tympanoplasty is the operation of choice where follow-up cannot be guaranteed.

D A type III tympanoplasty may leave a residual hearing loss of about $25 \mathrm{~dB}$.

E No ossicles are sacrificed in a modified radical mastoidectomy.

70 Management of cholesteatoma in children is difficult because

A Aural toilet is uncomfortable.

B Primary epithelialization of mastoid cavities is usual.

C There is a high frequency of nasopharyngeal infection.

D Excessive fibrosis causes narrowing of the meatoplasty.

E There is a high incidence of recurrence with combined approach tympanoplasty.

\title{
71 In an open mastoid cavity
}

A Healing takes place by secondary intention.

B Continuing otorrhoea may be due to an open eustachian tube.

C Obliteration with bone pate is usually successful even in the presence of otorrhoea.

D Complete eradication of cholesteatoma is not necessary if a pedicled muscle flap is used to obliterate the cavity.

E Only about $40 \%$ heal satisfactorily.

\section{Acute mastoiditis}

A There is a peak incidence around 11 years of age.

B Citelli's abscess occurs in the sternomastoid muscle.

C Sagging of the posterosuperior meatal wall is an important diagnostic sign.

D Parenteral penicillin is the antibiotic of choice.

E Schwartze operation may be required. 